\title{
Effect of processed and fermented soyabeans on net absorption in enterotoxigenic Escherichia coli-infected piglet small intestine
}

\author{
Jeroen L. Kiers ${ }^{1,2,3}$, M.J. Robert Nout ${ }^{1}$, Frans M. Rombouts ${ }^{1}$, Esther E. van Andel $^{2}$, Marius J.A. Nabuurs ${ }^{2}$ \\ and Jan van der Meulen ${ }^{2} *$ \\ ${ }^{1}$ Agrotechnology and Food Sciences Group of Wageningen UR, Laboratory of Food Microbiology, PO Box 8129, 6700 EV \\ Wageningen, The Netherlands \\ ${ }^{2}$ Animal Sciences Group of Wageningen UR, Animal Resources Development, PO Box 65, 8200 AB Lelystad, The Netherlands \\ ${ }^{3}$ Friesland Foods Western Europe, PO Box 159, 6710 BD Ede, The Netherlands
}

(Received 29 June 2005 - Revised 12 January 2006 - Accepted 3 February 2006)

\begin{abstract}
Infectious diarrhoea is a major problem in both children and piglets. Infection of enterotoxigenic Escherichia coli (ETEC) results in fluid secretion and electrolyte losses in the small intestine. In the present study the effect of processed and fermented soyabean products on net absorption during ETEC infection was investigated. Soyabean was processed into an autoclaved, a cooked and a mould-fermented (tempeh) product. The soyabean products were pre-digested and the effect of the products on net absorption in the small intestine of piglets was studied. Pairs of small-intestinal segments, one non-infected and the other ETEC-infected, were perfused simultaneously with the different products during $8 \mathrm{~h}$. Net absorption of fluid, DM, Na, chloride, $\mathrm{K}$ and total solutes was determined. Net fluid absorption was highest for cooked soyabean followed by autoclaved soyabean and tempeh as a result of the osmolality of these products. In ETEC-infected segments, cooked soyabean and tempeh showed minor fluid losses (27 (SE 23) and 43 (SE 20) $\mu \mathrm{l} / \mathrm{cm}^{2}$, respectively) compared with the saline control (260 (SE 23 ) $\mu 1 / \mathrm{cm}^{2}$ ). Tempeh resulted in a high uptake of solutes. Processed soyabean products, particularly cooked soyabean and tempeh, are beneficial in maintaining fluid balance during ETEC infection. Additionally, tempeh showed high DM and total solute absorption. Therefore, particularly, tempeh may be beneficial in the case of post-weaning diarrhoea in piglets and possibly in children as well.
\end{abstract}

Soyabeans: Enterotoxigenic Escherichia coli: Absorption: Pigs: Diarrhoea

The incidence of diarrhoea due to enteric pathogen infections is particularly high in less-developed countries and in individuals travelling to these regions. Diarrhoeal diseases claim nearly two million lives annually among children less than 5 years of age in areas of the world with poor hygiene (World Health Organization, 1999). Enterotoxigenic Escherichia coli (ETEC) is one of the main pathogens associated with severe diarrhoea (Bhan, 2000). ETEC secretes heat-labile and/or heat-stable enterotoxins resulting in net fluid loss and, ultimately, diarrhoea. Problems with acute diarrhoea also frequently occur in pig husbandry. In piglets ETEC is the main aetiological agent in both pre- and post-weaning diarrhoea (Hampson, 1994).

Tempeh is a traditional fermented food made from soaked and cooked soyabeans inoculated with a mould, usually of the genus Rhizopus (Nout \& Kiers, 2005). After fermentation has occurred, the soyabeans are bound together into a compact cake by dense cottony mycelium. An important function of the mould in the fermentation process is the synthesis of enzymes that hydrolyse soyabean constituents and contribute to the development of a desirable texture, flavour and aroma of the product. Enzymic hydrolysis also decreases or eliminates anti-nutritional factors and the nutritional quality is improved (Nout \& Kiers, 2005).

Tempeh contains antibacterial substances against grampositive bacteria (Wang et al. 1969, 1972; Kobayasi et al. 1992), and in vitro tempeh extracts are able to inhibit adhesion of ETEC to piglet small-intestinal brush border membranes (Kiers et al. 2002). Rabbits infected with ETEC and fed tempeh for 4 weeks showed reduced diarrhoea compared with rabbits fed diets without tempeh (Karmini et al. 1997), and in ETEC-challenged weaned piglets severity of diarrhoea was less on a diet with tempeh compared with a control diet containing toasted soyabeans (Kiers et al. 2003). Beneficial effects for tempeh have been reported in diarrhoea management in Indonesian children (Karyadi \& Lukito, 1996, 2000). Because of its protective effects during infection and its improved digestibility and nutrient availability, tempeh may be beneficial in the case of (post-weaning) diarrhoea and accelerating the recovery of young animals and young 
children, who are most at risk for ETEC diarrhoea and malnutrition.

Against the background of reported beneficial effects of tempeh in the control of diarrhoeal disease, in the present study the effect of processed and mould-fermented soyabean products on net absorption in non-infected and ETEC-infected piglet small intestine was investigated.

\section{Materials and methods}

\section{Soyabean products}

All products were produced from the same batch of soyabeans (Fig. 1). Dehulled yellow-seeded soyabeans (Glycine max) were soaked overnight in tap water using accelerated acidification (Nout et al. 1987). Subsequently, the beans were washed with tap water and cooked in fresh tap water at a 1:3 ratio for $20 \mathrm{~min}$, cooled and superficially dried at room temperature. Sporangiospore suspension was obtained by scraping off the sporangia from pure slant cultures of Rhizopus microsporus var. microsporus LU 573 grown on malt extract agar (CM 59; Oxoid, Basingstoke, Hants, UK) for $7 \mathrm{~d}$ at $30^{\circ} \mathrm{C}$ and suspending them in sterile distilled water with $0.85 \% \mathrm{NaCl}$ and $0.1 \%$ peptone. After inoculation of the cooked soyabeans with the sporangiospore suspension $(1 \%, \mathrm{v} / \mathrm{w})$ the beans $(450 \mathrm{~g})$ were packed into hard plastic perforated boxes $(205 \times 90 \times 45 \mathrm{~mm})$ and incubated at $30^{\circ} \mathrm{C}$ for $72 \mathrm{~h}$. Raw, cooked and fermented soyabeans were dried for $6 \mathrm{~h}$ at $60^{\circ} \mathrm{C}$, ground using a $1.0 \mathrm{~mm}$ screen and stored at $-20^{\circ} \mathrm{C}$ until use.

Pre-digestion was carried out as described earlier using $\alpha$-amylase, pepsin, lipase and pancreatin (Kiers et al. 2000).

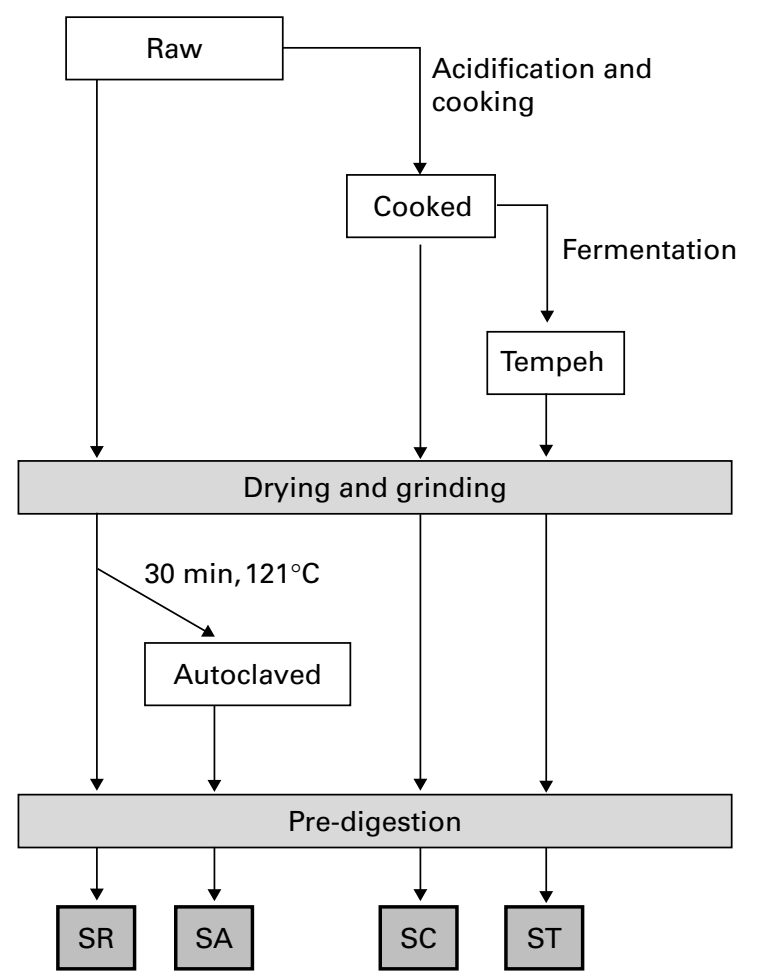

Fig. 1. Processing of soyabeans. SR, raw soyabean; SA, autoclaved soyabean; SC, cooked soyabean; ST, fermented soyabean (tempeh).
Autoclaved soyabean (SA) was prepared by autoclaving ground raw soyabean for $30 \mathrm{~min}$ at $121{ }^{\circ} \mathrm{C}$ and was subsequently pre-digested as was done for raw, cooked and fermented soyabean (Fig. 1). After pre-digestion the slurries were diluted using distilled water to approximately 6.5\% DM and kept at $4^{\circ} \mathrm{C}$ until use as perfusion products the next day.

\section{Net intestinal absorption}

All procedures involving animal handling and testing were reviewed and approved by the Animal Care and Ethics Committee of the Animal Sciences Group (Lelystad, The Netherlands).

Piglets (crossbred Yorkshire $\times($ Large White $\times$ Landrace $))$ were weaned at 3 weeks of age. They were transported to the institute and fed a standard piglet feed. Water containing colistin sulfate $(60 \mathrm{mg} / \mathrm{l}$; Colistine $1200 \mathrm{WO}$; Eurovet, Bladel, The Netherlands) was supplied ad libitum. At 2 weeks after weaning a biopsy from the duodenal mucosa was taken using a fiberscope (Olympus GIF XP10; Olympus, Hamburg, Germany) and F4 receptor status was determined (Sellwood et al. 1975). Piglets that expressed the F4 receptor involved in binding of the ETEC strain were used in the experiments 3 weeks after weaning.

The small-intestinal segment perfusion test was carried out essentially as described before (Nabuurs et al. 1993). The animal was tranquillised with $2 \mathrm{mg}$ azaperon/kg body weight (Stresnil ${ }^{\circledR}$; Janssen-Cilag BV, Tilburg, The Netherlands). Anaesthesia was induced and maintained throughout the whole experiment with sevoflurane (Sevorane $\AA$; Abbott BV, Amstelveen, The Netherlands) and nitrous oxide. The piglets were placed in dorsal recumbency on a heated surface, to control body temperature. The abdominal cavity was opened and the first intestinal segment was prepared approximately $75 \mathrm{~cm}$ caudal from the stomach. A small cranial tube (inflow; inner diameter $3 \mathrm{~mm}$; outer diameter $5 \mathrm{~mm}$ ) was placed and a wide tube (outflow; inner diameter $5 \mathrm{~mm}$; outer diameter $9 \mathrm{~mm}$ ) was placed $20 \mathrm{~cm}$ distal from the first. Caudal from and adjacent to this first segment, nine other segments were prepared in the same way. In this way the ten segments were situated between 9 (SE 2)\% and 34 (SE 4)\% of the total length of the small intestine. Between odd and even segments, $2 \mathrm{~cm}$ pieces of the intestine were removed for measurement of the circumference.

At $15 \mathrm{~min}$ before perfusion started the odd-numbered segments were injected with $5 \mathrm{ml}$ ETEC $\left(5 \times 10^{9}\right.$ colony-forming units $0149: \mathrm{K} 91: \mathrm{K} 88^{\mathrm{ac}}$ producing heat-labile and heat-stable enterotoxins in $5 \mathrm{ml} \mathrm{PBS}$ ) and the even-numbered segments

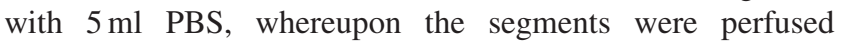
simultaneously.

Saline (supplemented with glucose $(1 \mathrm{~g} / \mathrm{l})$ and casamino acids (acid-hydrolysed casein; $1 \mathrm{~g} / \mathrm{l}$ ) to assure bacterial growth), pre-digested raw soyabean (SR), pre-digested SA, pre-digested cooked soyabean (SC), and pre-digested fermented soyabean (tempeh; ST) were tested in three experiments with four piglets each (total of twelve piglets). In each piglet, five pairs of segments (an ETEC-infected and an adjacent non-infected) were perfused using a Latin square design for the four soyabean products with saline, serving as an internal control to determine the maximum response to the infection, in the middle two segments. Saline served as an 
internal control to determine the maximum response of the piglet to infection.

Each segment was perfused with $64 \mathrm{ml}$ product over $8 \mathrm{~h}$, by injecting $2 \mathrm{ml}$ product every $15 \mathrm{~min}$. Non-absorbed and/or excreted material and fluid passed through the outflow tubes into corresponding drainage bottles placed at the same level as the piglet's abdomen. At the end of the experiment the product remaining in the segments was blown out into the corresponding drainage bottles (outflow). The piglets were killed by injection of $200 \mathrm{mg}$ sodium pentobarbital $/ \mathrm{kg}$ body weight (Dolethal ${ }^{\circledR}$; Vétoquinol BV, 's-Hertogenbosch, The Netherlands). The segments were cut from the mesenterium and the length was measured. Samples of $1 \mathrm{~cm}^{2}$ were cut from the segment and put into physiological salt solution. Decimal dilution series were made and appropriate dilutions were spread on heart infusion agar (Difco ${ }^{\mathrm{TM}}$; BD Diagnostics, Franklin Lakes, NJ, USA) supplemented with $5 \%$ of defibrinated sheep blood. Plates were incubated for $18-24 \mathrm{~h}$ at $37^{\circ} \mathrm{C}$ and haemolytic colonies were counted.

DM content of the products and outflows was determined by drying samples for $24 \mathrm{~h}$ at $80^{\circ} \mathrm{C}$ in triplicate. $\mathrm{Na}, \mathrm{K}$ and chloride concentrations of products and outflows were determined using an Electrolyte $4+$ analyser (Noval Biomedical, Waltham, MA, USA). Osmolality was determined using a cryoscopic osmometer (Osmomat; Gonotec GmbH, Berlin, Germany).

Net fluid, DM, Na, K, chloride and total solute absorption were calculated from the difference between the volume and concentration of inflow and outflow divided by the surface area (length $\times$ circumference) of each segment.

\section{Statistics}

Results of non-infected and ETEC-infected segments perfused with the same product were compared using the Student's paired $t$ test, whereas comparisons between different perfusion products were done with ANOVA. All statistics were performed with GraphPad Prism version 4.00 for Windows (2004; GraphPad Software, San Diego, CA, USA). Net absorption of fluid, DM, Na, K, chloride and total solutes are presented as mean values with their standard errors.

\section{Results}

Characteristics of the pre-digested processed and fermented soyabean products are shown in Table 1. SR and SA products were very similar. K content in SR and SA was much higher compared with SC and ST. Na and chloride content were highest for ST and lowest for SC. Osmolality was lowest for SC and almost double that value in ST.

Net fluid absorption was highest for SC followed by SA and ST, whereas SR showed the lowest fluid absorption (Table 2). Perfusion of SR resulted in significantly lower net fluid absorption values compared with SA despite equal product characteristics (Table 1). An inverse linear relationship was found between net fluid absorption and osmolality of the three pre-digested processed soyabean products (SA, SC and ST) both for the non-infected (fluid absorption $=844-1 \cdot 27 \times$ osmolality; $r^{2} 0.99$ ) and the ETEC-infected (fluid absorption $=808-1.33 \times$ osmolality; $\left.r^{2} 0.93\right)$ situation.

ETEC infection resulted in a decrease in net fluid absorption of 260 (SE 23) $\mu 1 / \mathrm{cm}^{2}$ for saline. Reduction in average net fluid absorption was much less pronounced in soyabean products (Table 2). For SC and ST, net fluid absorption in ETEC-infected segments was not significantly lower compared with the non-infected segments. All soyabean products appeared to protect to a certain extent against fluid loss upon ETEC infection (Fig. 2). Mean fluid loss was considerably smaller for SC and ST when compared with SR and SA.

Net DM absorption was higher from soyabean products compared with saline and was significantly higher for processed soyabean compared with SR (Table 2). Although ST showed higher net DM uptake compared with SA and SC, these differences were not significantly different. Net DM absorption was not significantly different between noninfected and ETEC-infected segments for all processed soyabean products, but was for saline and SR.

Perfusion of SR resulted in net secretion of $\mathrm{Na}$ in both noninfected and ETEC-infected segments (Table 2). Na uptake was similar for SA, SC and ST in non-infected segments and was significantly reduced in ETEC-infected segments, although the reduction for ST was less severe. In addition, chloride and $\mathrm{K}$ absorption was significantly reduced as a result of the ETEC-infection, except for $\mathrm{K}$ absorption in the segments perfused with SA.

Perfusion of saline resulted in high net total solute absorption (Fig. 3). The sum of the net absorption of $\mathrm{Na}$, chloride and $\mathrm{K}$ almost equalled the net total solute absorption for saline. SR showed net secretion of solutes in non-infected as well as ETEC-infected segments. Of all soyabean products ST showed highest net total solute absorption. It is clearly

Table 1. Characteristics of pre-digested raw (SR), autoclaved (SA), cooked (SC) and fermented (tempeh; ST) soyabean products* $^{*}$

(Mean values and standard deviations)

\begin{tabular}{|c|c|c|c|c|c|c|c|c|c|c|c|c|}
\hline \multirow[b]{2}{*}{ Product } & \multicolumn{2}{|c|}{$\mathrm{pH}$} & \multicolumn{2}{|c|}{$\mathrm{DM}(\% \mathrm{w} / \mathrm{w})$} & \multicolumn{2}{|c|}{$\mathrm{Na}(\mathrm{mm})$} & \multicolumn{2}{|c|}{$\mathrm{K}(\mathrm{mm})$} & \multicolumn{2}{|c|}{$\begin{array}{l}\text { Chloride } \\
(\mathrm{mm})\end{array}$} & \multicolumn{2}{|c|}{$\begin{array}{l}\text { Osmolality } \\
\text { (mOsmol/l) }\end{array}$} \\
\hline & Mean & SD & Mean & SD & Mean & SD & Mean & SD & Mean & SD & Mean & SD \\
\hline SR & $6 \cdot 3$ & 0.0 & 6.50 & 0.23 & 48 & 1 & 35.9 & $5 \cdot 8$ & 57 & 3 & 200 & 11 \\
\hline SA & $6 \cdot 2$ & 0.0 & 6.54 & 0.12 & 46 & 3 & 36.9 & $2 \cdot 8$ & 56 & 2 & 198 & 9 \\
\hline SC & $6 \cdot 1$ & 0.2 & $6 \cdot 39$ & 0.14 & 44 & 3 & $10 \cdot 4$ & $1 \cdot 1$ & 41 & 4 & 152 & 12 \\
\hline ST & $6 \cdot 1$ & 0.1 & 6.90 & 0.02 & 63 & 3 & $11 \cdot 7$ & 1.4 & 62 & 4 & 294 & 11 \\
\hline
\end{tabular}

* Mean values of three pre-digestions. 


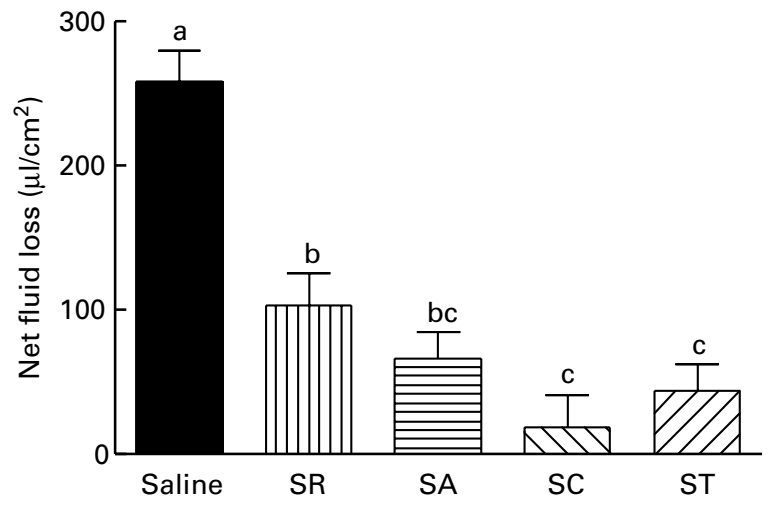

Fig. 2. Fluid loss upon enterotoxigenic Escherichia coli infection in piglet small-intestinal segments after perfusion with saline and pre-digested raw (SR), autoclaved (SA), cooked (SC) and fermented (tempeh; ST) soyabean products. Values are means, with their standard errors represented by vertical bars. Mean values with unlike letters were significantly different $(P<0.05)$.

shown that for all tested products, except for ST, a net secretion of solutes other than $\mathrm{Na}$, chloride and $\mathrm{K}$ is observed (Fig. 3). Apparently, tempeh was the only product showing significant absorption of solutes other than $\mathrm{Na}$, chloride and $\mathrm{K}$.

Bacteriological analysis of the mucosa from ETEC-infected segments showed high numbers of ETEC for all soyabean products (Table 3). Segments perfused with saline showed significantly lower ETEC numbers.

\section{Discussion}

Tempeh is a traditional fermented food made from soaked and cooked soyabeans inoculated with a mould. Considerable leaching of soluble DM occurs (Kiers et al. 2000), which explains the low K content of the cooked and fermented soyabean products. This leaching may also account for the rather low osmolality of SC. Osmolality is increased in ST as a result of breakdown of macromolecules during fermentation and the addition of excess $\mathrm{HCl}$ and $\mathrm{NaHCO}_{3}$ during the predigestion to adjust $\mathrm{pH}$ for the different enzymic degradation steps (Kiers et al. 2000).

High DM uptake during perfusion with tempeh might reflect an improved nutrient availability after fermentation as suggested before (Kiers et al. 2000). It was probably not the result of differences in osmolality and $\mathrm{Na}$ concentration between cooked soyabean and tempeh, because low osmolality does not affect the absorption rates of $\mathrm{N}$ and carbohydrate from nutrient solutions (Pfeiffer et al. 1998). Furthermore, the Na concentration of enteral diets does not influence the absorption of macronutrients and of total energy in miniature pigs (Ehrlein et al. 1999). When total net solute absorption was corrected for $\mathrm{Na}$, chloride and $\mathrm{K}$, only tempeh showed a positive balance, probably reflecting the uptake of easily accessible nutrients and/or minerals (Macfarlane et al. 1990; Mital \& Garg, 1990; Kiers et al. 2000).

The negative correlation between the osmolality of the processed soyabean products and net fluid absorption was shown earlier for oral rehydration solutions in rats (Hunt et al. 1991) and piglets (Kiers et al. 2001) and for oral rehydration solutions in which the glucose content had partially been 


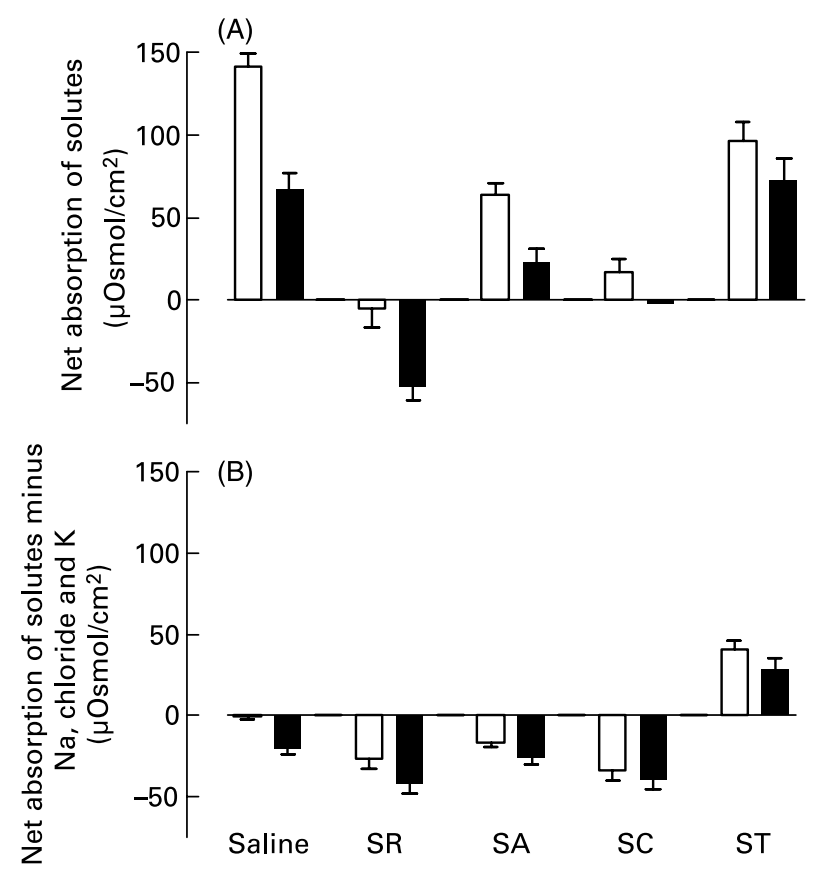

Fig. 3. Net absorption of total solutes (A) and of total solutes minus $\mathrm{Na}$, chloride and $\mathrm{K}(\mathrm{B})$ after perfusion with saline and pre-digested raw (SR), autoclaved (SA), cooked (SC) and fermented (tempeh; ST) soyabean products in non-infected ( $\square$ ) and enterotoxigenic Escherichia coli-infected ( $\square$ ) piglet small-intestinal segments. Values are means, with their standard errors represented by vertical bars.

replaced by amino acids or food supplements in rats (Pillai et al. $1994 a, b)$.

The difference in net fluid absorption between noninfected and ETEC-infected segments was higher for saline compared with the different soyabean products. The observed different protective effects of the soyabean products were not caused by their different osmolalities, since osmolality of a perfusion solution does not affect the degree of reduction in net fluid absorption due to ETEC infection (Kiers et al. 2001). Especially cooked soyabean and tempeh minimised the reduction in net fluid absorption in ETEC-infected segments.

Various modes of action may be involved in diminishing the fluid loss upon ETEC infection by soyabean products. First, compounds in the soyabean products may interfere

Table 3. Number of enterotoxigenic Escherichia coli (ETEC) attached to the infected segmental wall of piglet intestine after perfusion with saline and pre-digested raw (SR), autoclaved (SA), cooked (SC) and fermented (tempeh, ST) soyabean products

(Mean values with their standard errors)

\begin{tabular}{llr}
\hline & \multicolumn{2}{c}{ ETEC $\left(\log _{10} \mathrm{cfu} / \mathrm{cm}^{2}\right)$} \\
\cline { 2 - 3 } Product & Mean & SE \\
\hline Saline & $6 \cdot 55^{\mathrm{a}}$ & 0.34 \\
SR & $8 \cdot 25^{\mathrm{b}}$ & 0.18 \\
SA & $8.62^{\mathrm{b}}$ & 0.22 \\
SC & $8.90^{\mathrm{b}}$ & 0.19 \\
ST & $8.73^{\mathrm{b}}$ & 0.23
\end{tabular}

cfu, Colony-forming units.

${ }_{\mathrm{a}, \mathrm{b}}$ Mean values with unlike superscript letters were significantly different $(P<0.05)$ with attachment of ETEC to the enterocytes, as we showed for tempeh and pig brush borders in vitro before (Kiers et al. 2002). Second, the tempeh may still have proteolytic activity (proteases produced during fermentation) in the intestine that might inactivate ETEC receptors and consequently protect against ETEC-induced diarrhoea (Mynott et al. 1996, 1997; Chandler \& Mynott, 1998). However, since high numbers of ETEC were detected after sampling the intestinal wall after perfusion, probably no conclusive interference with the adhesion of ETEC occurred during perfusion with the soyabean products. Third, the presence of insoluble compounds such as fibres may have contributed by affecting viscosity and/or transit time (Go et al. 1994). However, soyabean contains only small amounts of viscous fibre (Ehrlein \& Stockmann, 1998) and also the viscosity of processed and fermented soyabean products is low (Osundahunsi \& Aworh, 2002). Fourth, soluble fibres have been shown earlier to enhance intestinal water and electrolyte absorption in normal and secreting rat small intestine (Rabbani et al. 1991; Wingertzahn et al. 1999; Turvill et al. 2000). Finally, the protective effect could have resulted from inhibition of intestinal secretion by interaction with the enterotoxin as was shown for factors from rain-tree (Hor et al. 1995), or by inhibition of chloride channels as was shown for low-molecular-weight factors from rice (Macleod et al. 1995; Mathews et al. 1999).

The environment induced by the processed soyabean products and/or the presence of specific compounds and/or (in)soluble fibres of the processed soyabeans may explain the protective effect of these soyabean products. Further research is required to uncover the mode of action by which especially soyabean tempeh and cooked soyabean protect against ETEC-induced fluid losses in piglets and possibly in children. 


\section{Acknowledgements}

The authors thank Gert-Jan de Graaf, Arie Hoogendoorn and Ank van Zijderveld-van Bemmel for their technical assistance. Financial support from the Dutch Ministry of Agriculture, Nature and Food Quality, as well as from Numico Research $\mathrm{BV}$, Wageningen, The Netherlands, is gratefully acknowledged.

\section{References}

Bhan MK (2000) Current and future management of childhood diarrhoea. Int J Antimicrob Agents 14, 71-73.

Chandler DS \& Mynott TL (1998) Bromelain protects piglets from diarrhoea caused by oral challenge with K88 positive enterotoxigenic Escherichia coli. Gut 43, 196-202.

Ehrlein H, Haas-Deppe B \& Weber E (1999) The sodium concentration of enteral diets does not influence absorption of nutrients but induces intestinal secretion of water in miniature pigs. J Nutr 129, 410-418.

Ehrlein H \& Stockmann A (1998) Intestinal absorption of nutrients is not influenced by soy fiber and does not differ between oligomeric and polymeric enteral diets. Dig Dis Sci 43, 2099-2110.

Go JT, Harper RG, Sia CG, Teichberg S \& Wapnir RA (1994) Oral rehydration solutions: increased water and sodium absorption by addition of a viscosity-enhancing agent in a rat model of chronic osmotic diarrhea. J Pediatr Gastroenterol Nutr 19, 410-416.

Hampson DJ (1994) Postweaning Escherichia coli diarrhoea in pigs. In Escherichia Coli in Domestic Animals and Humans, pp. 171-191 [CJ Gyles, editor]. Wallingford, UK: CAB International.

Hor M, Rimpler H \& Heinrich M (1995) Inhibition of intestinal chloride secretion by proanthocyanidins from Guazuma ulmifolia. Planta Med 61, 208-212.

Hunt JB, Carnaby S \& Farthing MJ (1991) Assessment of water and solute absorption from experimental hypotonic and established oral rehydration solutions in secreting rat intestine. Aliment Pharmacol Ther 5, 273-281.

Karmini M, Affandi E \& Hermana H (1997) The inhibitory effect of tempe on Escherichia coli infection. In Proceedings of the International Tempe Symposium, pp. 157-162 [S Sudarmadji, S Suparmo and S Raharjo, editors]. Jakarta, Indonesia: Indonesian Tempe Foundation.

Karyadi D \& Lukito W (1996) Beneficial effects of tempeh in disease prevention and treatment. Nutr Rev 54, S94-S98.

Karyadi D \& Lukito W (2000) Functional food and contemporary nutrition-health paradigm: tempeh and its potential beneficial effects in disease prevention and treatment. Nutrition 16, 697.

Kiers JL, Meijer JC, Nout MJ, Rombouts FM, Nabuurs MJ \& van der Meulen J (2003) Effect of fermented soya beans on diarrhoea and feed efficiency in weaned piglets. $J$ Appl Microbiol 95, 545-552.

Kiers JL, Nout RMJ \& Rombouts FM (2000) In vitro digestibility of processed and fermented soya bean, cowpea and maize. J Sci Food Agric 80, 1325-1331.

Kiers JL, Nout MRJ, Rombouts FM, Nabuurs MJA \& van der Meulen J (2001) Net absorption of fluid in uninfected and ETEC-infected piglet small intestine: effect of osmolality. In Digestive Physiology in Pigs. Proceedings of the 8th Symposium, pp. 277-279 [JE Lindberg and B Ogle, editors]. Wallingford, UK: CABI Publishing.

Kiers JL, Nout MJ, Rombouts FM, Nabuurs MJ \& van der Meulen J (2002) Inhibition of adhesion of enterotoxigenic Escherichia coli K88 by soya bean tempe. Lett Appl Microbiol 35, 311-315.

Kobayasi S, Okazaki N \& Koseki T (1992) Purification and characterization of an antibiotic substance produced from Rhizopus oligosporus IFO 8631. Biosci Biotechnol Biochem 56, 94-98.
Macfarlane BJ, van der Riet WB, Bothwell TH, Baynes RD, Siegenberg D, Schmidt U, Tal A, Taylor JR \& Mayet F (1990) Effect of traditional oriental soy products on iron absorption. Am J Clin Nutr 51, 873-880.

Macleod RJ, Bennett HP \& Hamilton JR (1995) Inhibition of intestinal secretion by rice. Lancet 346, 90-92.

Mathews CJ, MacLeod RJ, Zheng SX, Hanrahan JW, Bennett HP \& Hamilton JR (1999) Characterization of the inhibitory effect of boiled rice on intestinal chloride secretion in guinea pig crypt cells. Gastroenterology 116, 1342-1347.

Mital BK \& Garg SK (1990) Tempeh - technology and food value. Food Rev Int 6, 213-224.

Mynott TL, Guandalini S, Raimondi F \& Fasano A (1997) Bromelain prevents secretion caused by Vibrio cholerae and Escherichia coli enterotoxins in rabbit ileum in vitro. Gastroenterology 113, 175-184.

Mynott TL, Luke RK \& Chandler DS (1996) Oral administration of protease inhibits enterotoxigenic Escherichia coli receptor activity in piglet small intestine. Gut 38, 28-32.

Nabuurs MJ, Hoogendoorn A, van Zijderveld FG \& van der Klis JD (1993) A long-term perfusion test to measure net absorption in the small intestine of weaned pigs. Res Vet Sci 55, 108-114.

Nout MJR, De Dreu MA, Zuurbier AM \& Bonants-van Laarhoven TMG (1987) Ecology of controlled soybean acidification for tempe manufacture. Food Microbiol 4, 165-172.

Nout MJR \& Kiers JL (2005) Tempe fermentation, innovation and functionality: update into the third millennium. J Appl Microbiol 98, 789-805.

Osundahunsi OF \& Aworh OC (2002) A preliminary study on the use of tempe-based formula as a weaning diet in Nigeria. Plant Foods Hum Nutr 57, 365-376.

Pfeiffer A, Schmidt T \& Kaess H (1998) The role of osmolality in the absorption of a nutrient solution. Aliment Pharmacol Ther 12, 281-286.

Pillai GV, Brueton MJ, Burston D \& Sandhu BK (1994a) Evaluation of the effects of varying solute content on the efficacy of oral rehydration solutions in a rat model of secretory diarrhoea. $J$ Pediatr Gastroenterol Nutr 18, 457-460.

Pillai GV, Brueton MJ, Burston D \& Sandhu BK (1994b) Studies of water movement across the gut using oral rehydration solutions in a rat perfusion model. Aliment Pharmacol Ther 8, 555-558.

Rabbani GH, Lu RB, Horvath K \& Lebenthal E (1991) Shortchain glucose polymer and anthracene-9-carboxylic acid inhibit water and electrolyte secretion induced by dibutyryl cyclic AMP in the small intestine. Gastroenterology 101, $1046-1053$

Sellwood R, Gibbons RA, Jones GW \& Rutter JM (1975) Adhesion of enteropathogenic Escherichia coli to pig intestinal brush borders: the existence of two pig phenotypes. J Med Microbiol 8, 405-411.

Turvill JL, Wapnir RA, Wingertzahn MA, Teichberg S \& Farthing MJ (2000) Cholera toxin-induced secretion in rats is reduced by a soluble fiber, gum arabic. Dig Dis Sci 45, 946-951.

Wang HL, Ellis JJ \& Hesseltine CW (1972) Antibacterial activity produced by molds commonly used in oriental food fermentations. Mycologia 64, 218-221.

Wang HL, Ruttle DI \& Hesseltine CW (1969) Antibacterial compound from a soybean product fermented by Rhizopus oligosporus. Proc Soc Exp Biol Med 131, 579-583.

Wingertzahn MA, Teichberg S \& Wapnir RA (1999) Modified starch enhances absorption and accelerates recovery in experimental diarrhea in rats. Pediatr Res 45, 397-402.

World Health Organization (1999) World Health Organization Report on Infectious Diseases. Removing Obstacles to Healthy Development. Geneva: WHO. 